\title{
Abdominal pseudohernia: a manifestation of diabetic truncal radiculoneuropathy
}

\author{
Partha Pratim Chakraborty, ${ }_{1}$ Arijit Singha, ${ }^{2}$ Rana Bhattacharjee, ${ }_{1}$ \\ Subhankar Chowdhury ${ }^{2}$
}

'Department of Medicine, Midnapore Medical College and Hospital, Midnapore, West Bengal, India

${ }^{2}$ Department of Endocrinology \& Metabolism, Institute of Post Graduate Medical Education and Research/SSKM Hospital Kolkata, West Bengal, India

\section{Correspondence to} Dr Partha Pratim Chakraborty, docparthapc@yahoo.co.in

Accepted 30 May 2016
CrossMark

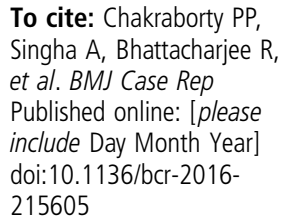

\section{DESCRIPTION}

A 65-year-old non-obese (body mass index $22.8 \mathrm{~kg} / \mathrm{m}^{2}$ ) man with a long history of type 2 diabetes noticed unilateral, dull aching pain over the left side of his upper abdomen for 3 months and subsequent swelling overlying the area (figure 1), which prompted him to seek surgical consultation. A working diagnosis of lumbar hernia with uncontrolled diabetes (fasting, postprandial plasma glucose and glycosylated haemoglobin levels were $265 \mathrm{mg} / \mathrm{dL} \quad(14.7 \mathrm{mmol} / \mathrm{L})$, $382 \mathrm{mg} / \mathrm{dL}(21.2 \mathrm{mmol} / \mathrm{L})$ and $11.2 \%$ (NGSP) (IFCC $98.9 \mathrm{mmol} / \mathrm{mol}$ ) respectively) was made and he was referred for glycaemic control. The dull aching pain involving the T7-T10 spinal segments was worse at night. The patient had undergone documented weight loss of $8 \mathrm{~kg}$ over the previous 3 months. He had no underlying organomegaly and the swelling was not evident on lying in the right lateral decubitus position (figure 2). The patient had diminished cutaneous sensations (fine touch, crude touch and temperature) involving the left-sided T7-T10 dermatomes overlying the swelling. He also had distal symmetric peripheral neuropathy as evidenced clinically by loss of vibration sense below his knees, using a $128 \mathrm{~Hz}$ tuning fork, diminished ankle reflexes and vibration perception threshold (VPT) of $45 \mathrm{~V}$ bilaterally, using a biothesiometer (VPT of $>25 \mathrm{~V}$ is considered abnormal). Direct ophthalmoscopy by a trained ophthalmologist revealed bilateral moderate non-proliferative diabetic retinopathy with clinically significant macular oedema, which was confirmed subsequently by fundus fluorescein angiography and optical coherence tomography. Abdominal ultrasound and CT scan of the abdomen revealed neither mass nor overlying

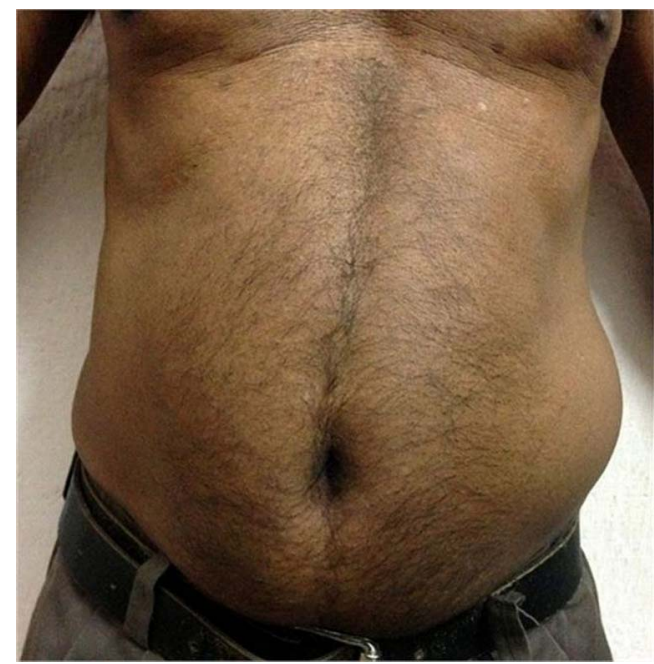

Figure 1 Unilateral swelling on the left side of the abdomen in the upright posture.

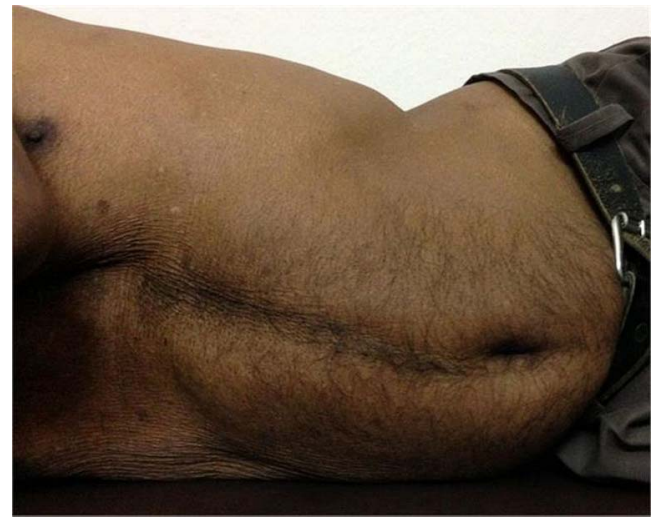

Figure 2 Disappearance of swelling on lying in the right lateral decubitus position.

fascial defect. Subsequent electrophysiology revealed fibrillation potential, and prolonged and high amplitude motor unit action potentials suggestive of truncal polyradicular neuropathy, along with features of axonal sensorimotor polyneuropathy involving all four limbs (figure 3). With exclusion of any obvious cause of the abdominal swelling and features of advanced microangiopathic complications in the background of long-standing uncontrolled type 2 diabetes, a diagnosis of diabetic truncal radiculoneuropathy with abdominal pseudohernia was made. The patient was prescribed a basal-bolus insulin regime for achieving glycaemic control along with pregabalin and amitriptyline for pain relief.

Diabetic truncal radiculoneuropathy, also called thoracoabdominal neuropathy, is a rarely recognised microvascular complication of diabetes. ${ }^{12}$ It is characterised by pain and/or dysaesthesia involving one or more dermatomes of the trunk with characteristic night-time worsening and, at times, subsequent abdominal bulging. Depending on the dermatomes involved, patients may present with chest, abdominal or perineal pain and dysaesthesia, and the discomfort felt in the chest or the abdomen may be confused with pain of cardiac, pulmonary or gastrointestinal origin. This subtype of diabetic neuropathy is often misdiagnosed and authors emphasise that diabetic truncal radiculoneuropathy be considered in the differential diagnosis of unexplained abdominal pain or asymmetrical abdominal swelling in patients with diabetes. It is a self-limiting disease with favourable outcome; pain usually subsides within months to a maximum of $1.5-2$ years and requires no surgical interventions. ${ }^{3}$ However, as in all other diabetic neuropathies, pain associated with truncal radiculoneuropathy can at times be severe and very difficult to control with commonly used first-line agents for pain relief. 
Figure 3 Prolonged and high amplitude polyphasic motor unit action potentials on electromyography.

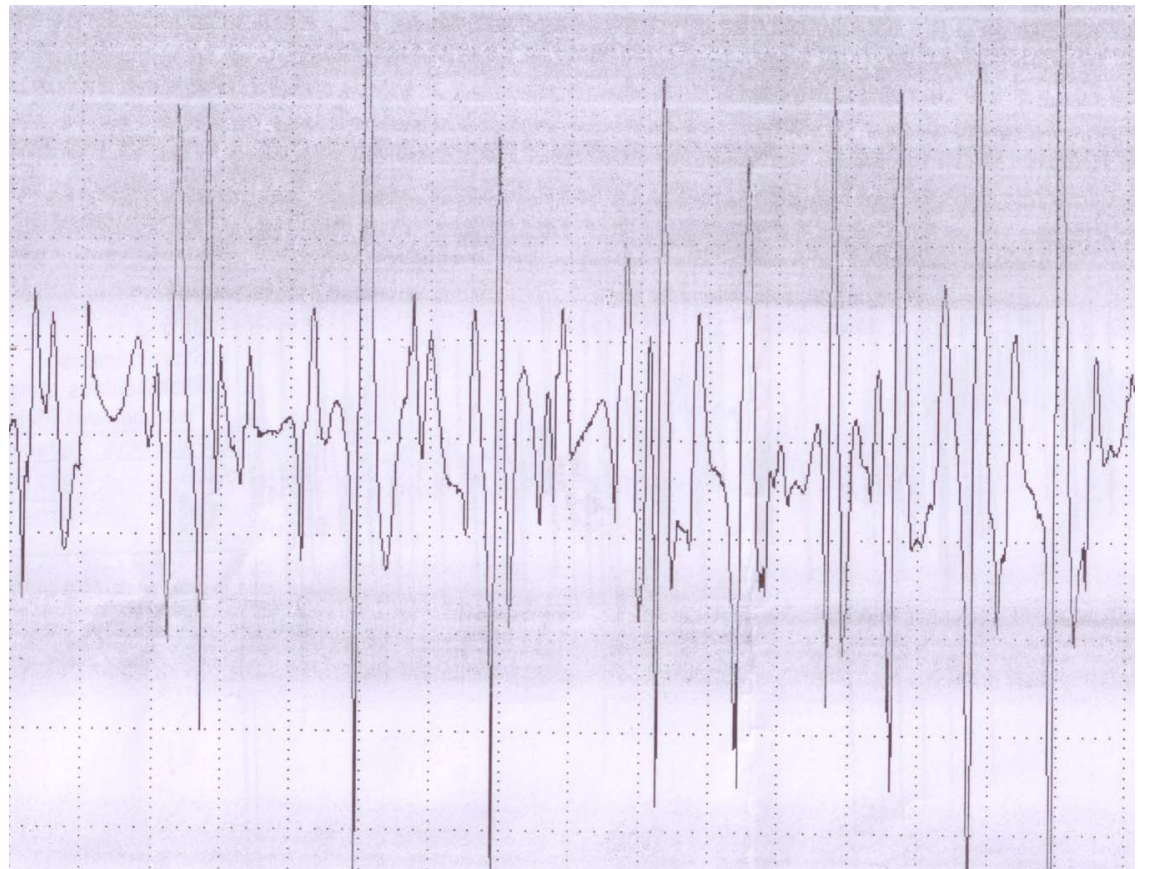

\section{Learning points}

- Diabetic truncal radiculoneuropathy, a form of asymmetric diabetic neuropathy, is an infrequently encountered clinical entity.

- Patients with uncontrolled diabetes and advanced microvascular complications are more likely to manifest this unusual form of neuropathy.

- Diabetic truncal radiculoneuropathy may present with or cause an abdominal pseudohernia, and a correct and timely diagnosis avoids unnecessary surgical interventions.
Contributors All the authors were involved in patient management. PPC, AS and $\mathrm{RB}$ conducted the literature search and wrote the manuscript. SC provided intellectual input and finalised the draft.

Competing interests None declared.

Patient consent Obtained.

Provenance and peer review Not commissioned; externally peer reviewed.

\section{REFERENCES}

1 Weeks RA, Thomas PK, Gale AN. Abdominal pseudohernia caused by diabetic truncal radiculoneuropathy. J Neurol Neurosurg Psychiatry 1999;66:405.

2 Chiu HK, Trence DL. Diabetic neuropathy, the great masquerader: truncal neuropathy manifesting as abdominal pseudohernia. Endocr Pract 2006;12:281-3.

3 Asbury AK. Focal and multifocal neuropathies of diabetes. In: Dyck PJ, Thomas PK, Asbury AK, et al, eds. Diabetic neuropathy. Philadelphia: Saunders, 1987:45-55.

Copyright 2016 BMJ Publishing Group. All rights reserved. For permission to reuse any of this content visit http://group.bmj.com/group/rights-licensing/permissions.

BMJ Case Report Fellows may re-use this article for personal use and teaching without any further permission.

Become a Fellow of BMJ Case Reports today and you can:

- Submit as many cases as you like

- Enjoy fast sympathetic peer review and rapid publication of accepted articles

- Access all the published articles

- Re-use any of the published material for personal use and teaching without further permission

For information on Institutional Fellowships contact consortiasales@bmjgroup.com

Visit casereports.bmj.com for more articles like this and to become a Fellow 